\title{
BASE CARTOGRÁFICA DIGITAL COMO INSTRUMENTO PARA A IDENTIFICAÇÃO DE ÁREAS SUSCETÍVEIS À EROSÃO E MOVIMENTOS DE MASSA EM JOÃO PESSOA (PB), BRASIL
}

\author{
CARTOGRAPHIC DIGITAL BASE AS A TOOL FOR \\ IDENTIFYING AREAS PRONE TO EROSION AND MASS \\ MOVEMENT IN JOÃO PESSOA (PB), BRAZIL
}

Saulo Roberto de Oliveira Vital ${ }^{1}$
Bruno Ferreira $^{2}$
Universidade Federal do Rio Grande do Norte/Brasil
Osvaldo Girão
Caio Lima dos Santos ${ }^{4}$
Universidade Federal de Pernambuco/Brasil
Fábio Carvalho Nunes ${ }^{5}$
Instituto Federal de Educação, Ciência e Tecnologia Baiano/Brasil
Thyago de Almeida Silveira ${ }^{6}$
Instituto Federal de Educação, Ciência e Tecnologia da Paraiba

1 Doutor em Geociências/Professor do Departamento de Geografia/Centro de Ensino Superior do Seridó/ Universidade Federal do Rio Grande do Norte/Brasil. E-mail: srovital@gmail.com.

2 Doutor em Geociências/Professor do Departamento de Geografia/Centro de Ensino Superior do Seridó/ Universidade Federal do Rio Grande do Norte/Brasil. E-mail: brunge2005@gmail.com.

3 Doutor em Geografia/Professor do Departamento de Geografia/Centro de Filosofia e Ciências Humanas/ Universidade Federal de Pernambuco/Brasil. E-mail: osgirao@gmail.com.

4 Mestre em Geografia/Doutorando do Programa de Pós-Graduação em Geografia/Universidade Federal de Pernambuco/Brasil. E-mail: caiolima21@hotmail.com.

5 Doutor em Geologia/Professor do Instituto Federal de Educação, Ciência e Tecnologia Baiano/Brasil. E-mail: fabio.nunes@si.ifbaiano.edu.br.

6 Mestre em Ciências Geodésicas e Tecnologia da Informação/Professor do Instituto Federal de Educação, Ciência e Tecnologia da Paraíba/Brasil. E-mail: thyago.silveira@gmail.com 
Saulo Roberto de Oliveira Vital, Bruno Ferreira, Osvaldo Girão, Caio Lima dos Santos, Fábio Carvalho Nunes. Cartographic digital base as a tool for identifying areas prone to erosion and mass movement in João Pessoa (PB), Brazil

\section{RESUMO}

O presente estudo teve como objetivo, realizar a detecção dos riscos de erosão e movimentos de massa no município de João Pessoa (PB), a partir de técnicas de geoprocessamento. Para isso, foram confeccionados mapas temáticos contendo informações referentes à cobertura do solo, declividade, exposição de vertentes e solos, gerados a partir de imagens do satélite OLI/Landsat e de cartas topográficas. A partir dessas informações foi possível observar que os riscos analisados são basicamente representados por erosões lineares e por desmonte nas encostas e terraços fluviais. Os resultados obtidos mostram uma série de riscos no cotidiano da população residente nessas áreas, merecendo ações que visem a mitigação ou extinção desses riscos. Entende-se assim, que esta temática carece da realização de estudos mais detalhados que ajudem na caracterização, previsão, monitoramento, recuperação e extinção desses problemas socioambientais.

Palavras-chave: risco, erosão, movimentos de massa, João Pessoa (PB), Brasil.

\section{ABSTRACT}

This study aims at identifying the risks of erosion and mass movement in the city of João Pessoa (PB) by using geoprocessing techniques. To do this, thematic maps comprising information about soil covering, declivity, exposure of slopes and soils were generated from OLI/Landsat images and topographic charts. Based on this information, it was possible to observe that the analyzed risks are basically represented by linear erosion and by the dismantle on the slopes and river terraces. The results obtained show a series of risks in the day to day of the population living in these areas, thus requiring actions that may mitigate or extinct theses risks. Therefore, it is understood that this issue needs more detailed studies that may help in the characterization, prediction, monitoring, recovering, and extinction of theses socio-environmental problems.

Keywords: risk, erosion, mass movement, João Pessoa (PB), Brazil.

\section{Introdução}

A Geomorfologia Urbana, enquanto ramo emergente da Geografia Física, busca elucidar as relações existentes entre os fatores físicos da paisagem e os impactos gerados pela ocupação antrópica, notadamente em espaços urbanizados, que são responsáveis por ocasionar a aceleração dos processos geomorfológicos, podendo, muitas vezes, assumir um caráter catastrófico (Guerra; Marçal, 2006; Guerra, 2011).

Nesse contexto, o risco surge como produto da associação entre as características naturais e os diversos tipos de usos, sendo intensificado pela ocupação desordenada, devido à ausência de planejamento urbano. Neste aspecto, o relevo constitui fator limitante à ocupação, sobretudo em unidades mais vulneráveis, tais como: planícies fluviais e vertentes.

Por essa razão, a ocupação de quaisquer parcelas do relevo exige um planejamento adequado e o monitoramento ambiental, tendo em vista que, a partir da apropriação de um determinado espaço, serão acrescidas facetas 
da dinâmica social às interações do sistema natural, provocando a aceleração dos processos geomorfológicos, culminando em rápidas mudanças de variadas magnitudes sobre o meio físico.

A partir das intervenções antrópicas na dinâmica do meio físico, em decorrência da expansão do processo de uso e ocupação da terra, tem-se uma intensificação de eventos naturais, tais como: processos erosivos, movimentos de massa, erosão costeira, enchentes e inundações. A expansão das paisagens culturais acaba por promover a aceleração de processos superficiais e o aumento à suscetibilidade a riscos, na forma de prejuízos ao aparato infraestrutural ou diretamente às pessoas afetadas.

A alteração da drenagem de uma área ocupada poderá desencadear uma aceleração nas respostas dos sistemas geomorfológicos aos eventos naturais, com respectiva intensificação de processos superficiais, originando um perigo potencial, trazendo consequências sociais e/ou econômicas. Quando da possibilidade da ocorrência de um evento natural tido como perigoso e, portanto, capaz de produzir prejuízos, ou danos para o espaço físico e social diretamente afetado, não só durante a vigência do evento em si, mas mesmo a médio e longo-prazo, tem-se o chamado risco natural, sendo o perigo resultante da vulnerabilidade natural e humana a tais eventos (Girão, Corrêa, Nóbrega \& Duarte, 2013).

A importância atribuída aos riscos geomorfológicos, nomeadamente aos movimentos de vertente, frente à ocorrência de desastres no Brasil nos últimos anos, em anos chuvosos, demanda a necessidade de iniciativas de mapeamento dos riscos para auxílio da gestão do território (Garcia, Zêzere, Oliveira \& Reis, 2007).

Isso se faz necessário, sobretudo nas capitais brasileiras, onde o avanço da urbanização tem sido crescente, tornando necessárias ações de planejamento que visem o bem estar social e a conservação dos sistemas naturais.

Nesse contexto, as técnicas de Geoprocessamento têm se revelado eficientes, uma vez que tornam possível o zoneamento de áreas suscetíveis à riscos a partir da relação entre diferentes variáveis ambientais, tais como: geologia, clima, solos, relevo e uso do solo.

Neste trabalho, foram relacionadas informações geomorfológicas, tais como declividade e orientação de vertentes, com informações de cobertura do solo e tipos solos, para a delimitação de áreas suscetíveis à ocorrência de erosão e movimentos de massa no município de João Pessoa (PB). 


\section{Localização e caracterização da área em estudo}

O município de João Pessoa encontra-se localizado na mesorregião da Mata Paraibana, no retângulo envolto pelas coordenadas UTM 282018 $\mathrm{mE} 9219876 \mathrm{mN}$ e $302762 \mathrm{mE} 9198434 \mathrm{mN}$, fuso $25 \mathrm{sul}$, sendo limitado a sul pelo município de Conde, a norte pelo município de Santa Rita, a oeste pelos municípios de Bayeux e Santa Rita e a leste pelo Oceano Atlântico. A altitude média em relação ao nível do mar é de 66 metros, com predominância de terrenos planos (figura 1).

Sua geologia encontra-se inserida no contexto da Bacia Sedimentar da Paraíba, cuja sucessão sedimentar é principiada por arenitos fluviais e fluvio-lacustres da Formação Beberibe que repousam diretamente sobre o embasamento cristalino, seguidos por arenitos calcíferos da Formação Itamaracá, calcários compactos sem influência de siliciclastos correspondentes à Formação Gramame e calcários magnesianos da Formação Maria Farinha (Barbosa et al., 2007).

Recobrindo os depósitos mencionados, encontra-se os sedimentos areno-argilosos da Formação Barreiras, constituídos por uma sequência notável e contínua de sedimentos pouco consolidados, variando entre argilas e conglomerados (Mabesoone; Rolim, 1982).

A geomorfologia da área encontra-se inserida no contexto do Setor Oriental Úmido e Subúmido, abarcando as áreas sedimentares marinhas e fluviomarinhas (formações recifais, baixada litorânea, com praias, restingas, dunas a mangues), áreas sedimentares continentais (baixo planalto costeiro com superfície preservada e dissecada, colinas residuais e falésias e planícies aluviais) (Carvalho, 1982).

O clima da área corresponde ao tipo Tropical Litorâneo, úmido e quente, apresentando maiores índices de pluviosidade nos meses de Abril, Junho e Julho, com normal histórica de precipitação de 2.145,4mm (Pereira et al., 2012).

Em relação aos solos, predominam os tipos: Podzólico Vermelho-Amarelo (Argissolos), com maior ocorrência na área de estudo, seguido dos Solos Indiscriminados de Mangue (Organossolos), Areias Quartzosas (Neossolos) e Podzol Hidromórfico (Espodossolos) (UEP RECIFE, 2006).

Na Paraíba, o tipo Podzólico Vermelho-Amarelo enquadra-se, em sua maioria, na categoria Argissolo Amarelo, pois apresenta horizonte B 

cartográfica digital como instrumento para a identificação de áreas suscetíveis à erosão e movimentos de massa em João Pessoa (pb), Brasil

textural, perfis moderadamente drenados e argila de atividade baixa (Campos; Queiroz, 2006; Mendonça et al., 2006).

Os Organossolos, por sua vez, estão no domínio das áreas de manguezais e apresentam como características principais: a ocorrência de horizontes orgânicos de cores escuras, predominância de estruturas granulares e condições de umidade e saturação prolongadas nos horizontes subsuperficiais (Cipriano-Silva et al., 2014).

Os Neossolos Quartzarênicos correspondem às Areias Quartzosas, que apresentam, geralmente, mais de 2 metros de profundidade, com baixo teor de matéria orgânica no horizonte $\mathrm{A}$, repousando sobre um horizonte $\mathrm{C}$ pouco desenvolvido, bastante rico em quartzo. Em geral, são solos pouco coerentes, constituído basicamente por grãos de areias simples (Spera et al., 1999). 
Saulo Roberto de Oliveira Vital, Bruno Ferreira, Osvaldo Girão, Caio Lima dos Santos, Fábio Carvalho Nunes. Cartographic digital base as a tool for identifying areas prone to erosion and mass movement in João Pessoa (PB), Brazil

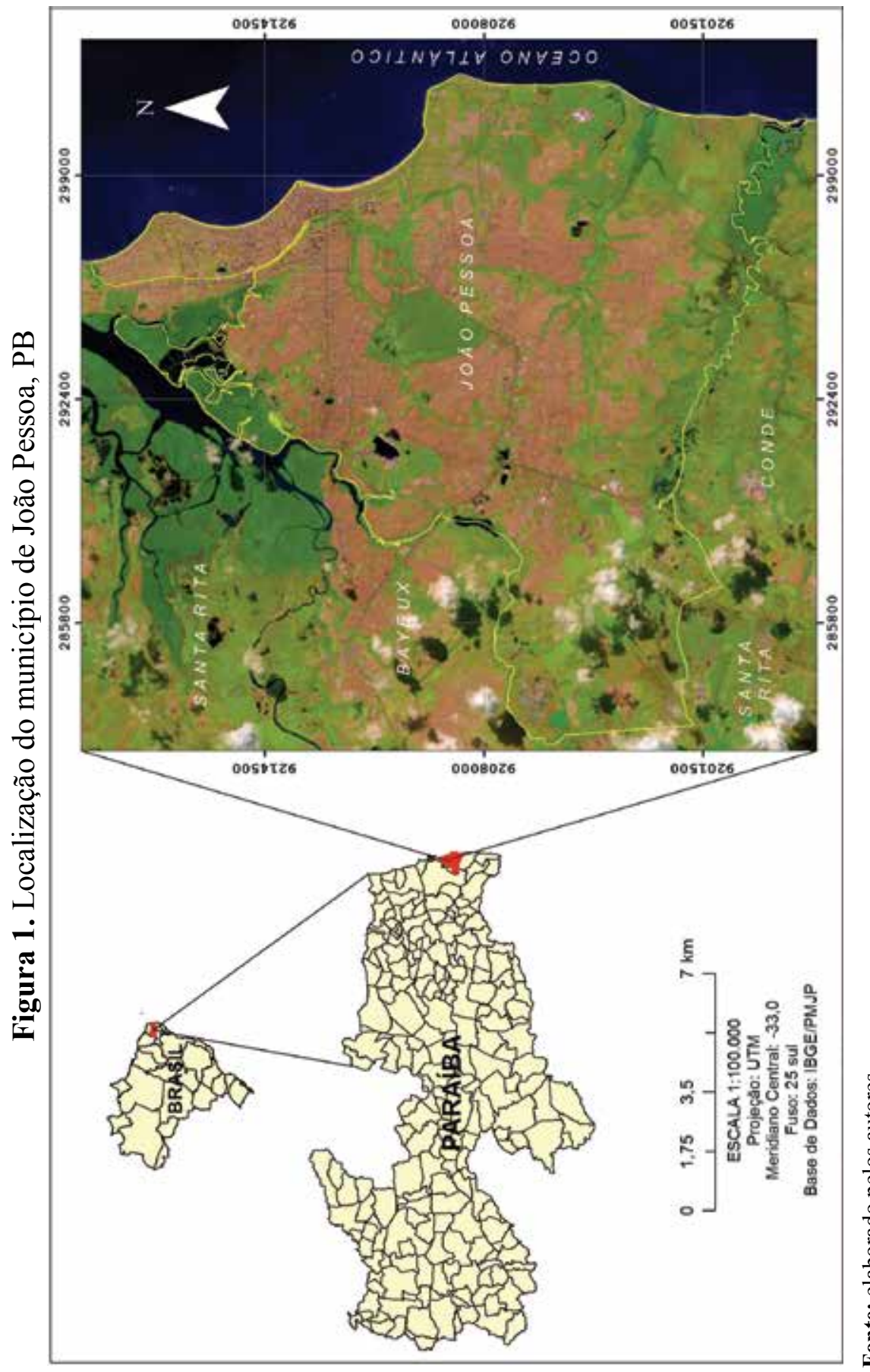

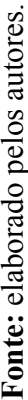


A vegetação é composta, em sua maioria, por remanescentes de Floresta Atlântica, onde se observa uma cobertura heterogênea, com indivíduos de 5 a 10 metros de altura, tendo como principais espécies: Rubiaceae, Fabaceae, Anacardiaceae e Boraginaceae. No entanto, em virtude da urbanização, este domínio já se encontra bastante alterado, onde também se observa espécies secundárias, tais como: Cecropia sp., Miconia albicans Triana e a Miconia calvensis DC. (Pereira; Alves, 2007). Além disso, também estão presentes espécies de Manguezal, com forte ocorrência nos estuários do rio Paraíba do Norte e Gramame, além de pequenas manchas de Cerrado no topo dos tabuleiros costeiros (Melo et al., 2001).

Em relação à hidrografia, o município de João Pessoa abrange o domínio das bacias hidrográficas dos rios: Jaguaribe, Marés Sanhauá, Gramame, Cuiá, Jacarapé, Aratu e Cabelo. Dentre estas, a maioria se encontra sobre os domínios urbanos, a exemplo da bacia do rio Jaguaribe, onde se verifica a ocorrência de diversas áreas vulneráveis à ocorrência de inundações, erosões e movimentos de massa (Oliveira, 2001; PMJP, 2015, Santos et al., 2015).

Em relação à população, de acordo com dados de 2010, João Pessoa conta com uma população total de 723.515 habitantes, sendo que parte desta população se encontra distribuída em aglomerados de habitações subnormais, comprimidas entre acidentes geográficos (Rosa, 2003; Censo, 2010).

\section{Metodologia}

O presente trabalho foi desenvolvido com base na análise integrada da paisagem por sobreposição de integrantes morfopedológicos e antrópicos, objetivando a delimitação de compartimentos homogêneos suscetíveis à ocorrência de erosão e movimentos de massa (figura 2).

Os mapas de declividade e exposição de vertentes foram elaborados com base em curvas de nível com equidistância de 5 metros, contidas em cartas topográficas de escala 1:10.000, gentilmente cedidas pelo Instituto de Terras e Planejamento Agrícola do Estado da Paraíba (INTERPA), além de imagens do satélite OLI/Landsat obtidas gratuitamente no Catálogo de Imagens do Instituto Nacional de Pesquisas Espaciais (INPE).

As curvas de nível do terreno foram utilizadas para a geração de uma Rede Triangular Irregular (TIN), com o intuito de confeccionar os mapas de declividade e exposição de vertentes. 
Figura 2. Organograma representando a metodologia adotada

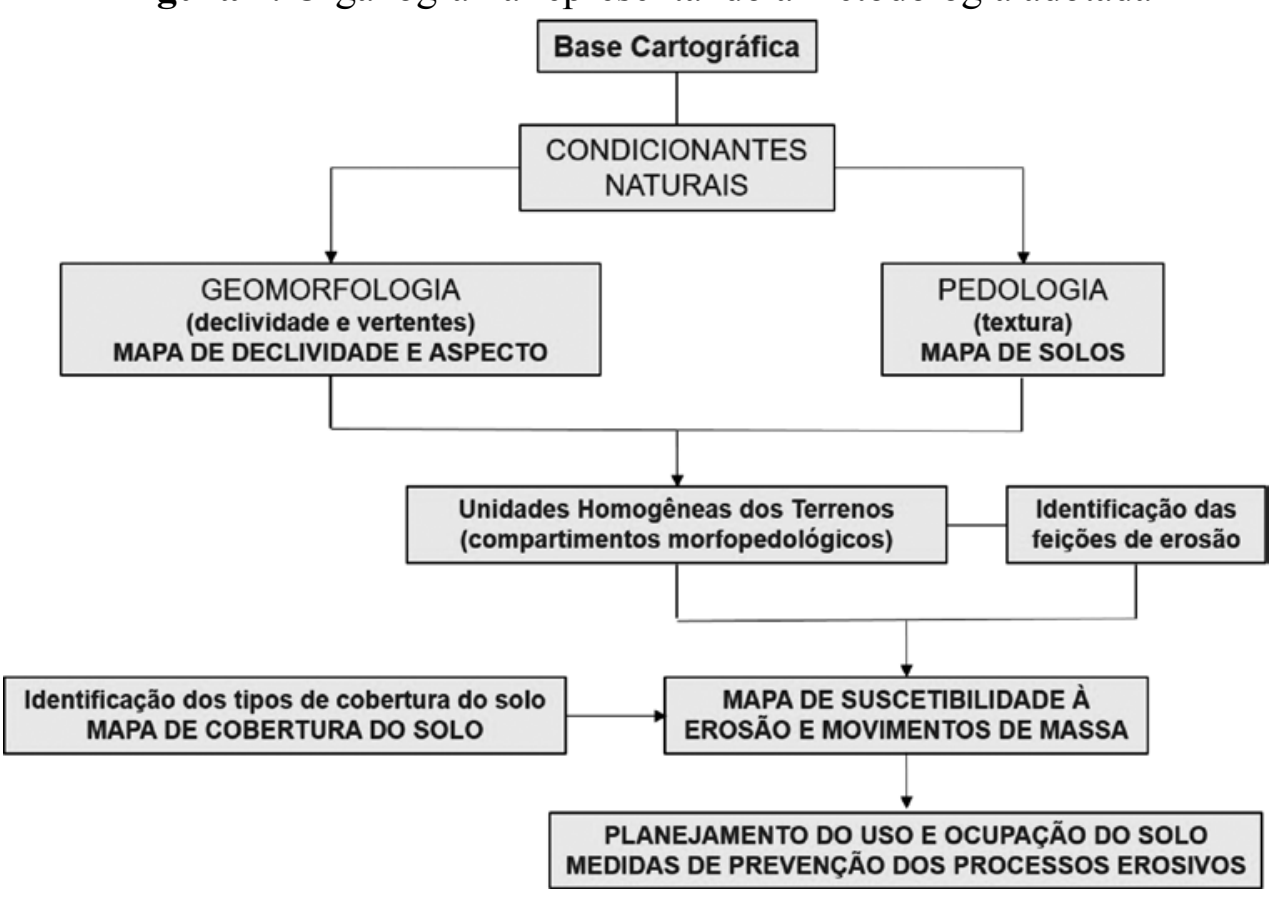

Fonte: adaptado de Macedo (2001).

As classes de declividade adotadas obedeceram sistematicamente à proposta metodológica descrita em Pereira e Lombardi-Neto (2004), contendo a seguinte legenda: plano (0-3\%), suave ondulado (3-8\%), moderadamente ondulado (8-13\%), ondulado (13-20\%), forte ondulado (20-45\%) e montanhoso ou escarpado $(>45)$.

O mapa de orientação das vertentes foi gerado com o intuito de averiguar a exposição das vertentes aos ventos litorâneos, uma vez que essas áreas são mais suscetíveis à ação da pluviosidade, tornando-as mais propensas à ocorrência de erosão e movimentos de massa.

O mapa de solos foi gerado com base no Mapa Exploratório-Reconhecimento de Solos do Município de João Pessoa, disponibilizado pela Empresa Brasileira de Pesquisa Agropecuária (EMBRAPA), UEP Recife (2006).

Após a aquisição do mapa, foi realizado o georreferenciamento e a vetorização das classes de solos, visando refiná-lo, ajustando-o à escala do mapeamento, com apoio no Modelo Digital de Elevação e nas curvas de nível. 
Para a definição das áreas suscetíveis à ocorrência de erosão e movimentos de massa, foi realizado um processo de álgebra de mapas, a partir da determinação zonas de baixo, médio e alto risco.

Para a correlação entre os mapas, foram utilizados os pesos apresentados na tabela 1.

Tabela 1. Pesos utilizados para os mapas temáticos no processo de álgebra

\begin{tabular}{|l|c|}
\hline \multicolumn{1}{|c|}{ Classes } & Pesos \\
\hline Declividade & 0,35 \\
\hline Cobertura da terra & 0,30 \\
\hline Solos & 0,20 \\
\hline Orientação de vertentes & 0,15 \\
\hline
\end{tabular}

Fonte: elaborado pelos autores.

Os respectivos pesos foram escolhidos com base no grau de importância de cada uma das variáveis apresentadas para a ocorrência dos processos analisados.

O peso 0,35 foi atribuído à declividade, pois seu grau de influência na ocorrência de movimentos de massa, devido à ação da gravidade, é bastante elevado. A cobertura da terra recebeu o peso 0,30 , pois a urbanização e outros tipos de coberturas são determinantes na intensificação dos processos erosivos. Os solos, por sua vez, receberam peso 0,20 , pelo fato de suas características exercem forte influência sobre os processos estudados, porém, com grau inferior à ocupação, pois a perda de solo verificada na região tem origem direta com a erosão hídrica acelerada. A orientação de vertentes, por fim, apresentou peso 0,15 devido sua participação na geração dos processos mencionados, principalmente durante a ocorrência de eventos climáticos excepcionais, porém bastante difícil de ser mensurada. Ambos os pesos foram combinados de forma a alcançar o valor total igual a 1 .

Além disso, foram atribuídos pesos individuais a cada uma das classes dos respectivos mapas, levando em consideração a influência de cada uma das mesmas para a ocorrência dos processos analisados (tabela 2).

$\mathrm{O}$ peso 1 foi atribuído às áreas onde as condições de declividade, a presença de vegetação, a exposição de vertentes e as características de solos favorecem à estabilidade morfodinâmica. $\mathrm{O}$ peso 3 , por outro lado, foi aferido às zonas detentoras de forte instabilidade, onde os processos de erosão e 
movimentos de massa são bastante atuantes, a exemplo das zonas fortemente inclinadas e densamente urbanizadas. Obviamente, o peso 2 foi aplicado às regiões consideradas como detentoras de grau intermediário de instabilidade.

Tabela 2. Pesos atribuídos às classes dos mapas temáticos

\begin{tabular}{|l|l|l|l|l|}
\hline Pesos & Declividade & Cobertura da terra & \multicolumn{1}{|c|}{ Solos } & Exposição de vertentes \\
\hline 1 & $0-3 \%$ & Floresta & Mineração & Plano \\
1 & $3-8 \%$ & $\begin{array}{l}\text { Água } \\
\text { Nuvens }\end{array}$ & Organossolos & SW, W, NW \\
1 & & Vegetação secundária & Espodossolos & N, S \\
\hline 2 & $8-13 \%$ & & & \\
2 & $13-20 \%$ & Urbanização & Argissolos & SE, E, NE \\
\hline 3 & $20-45 \%$ & & Neossolos & \\
\hline
\end{tabular}

Fonte: elaborado pelos autores.

No caso específico da declividade, o peso 1 foi atribuído às zonas com menor grau de inclinação, até $8 \%$ (regiões planas e suave onduladas). As áreas de 8-20\% (moderadamente onduladas e onduladas) foram estimadas como detentoras de grau intermediário de instabilidade, tendo em vista que essas regiões já possuem certo nível de transporte e erosão. Para as áreas com valores de declividade entre $20-100 \%$ foi atribuído o peso 3 , pois a legislação vigente considera que os setores acima de $30 \%$ são impróprios à ocupação.

No mapa de cobertura do solo, as áreas florestais receberam peso 1 devido à estabilidade que fornecem à paisagem, impedindo o início do processo erosivo, na maioria dos casos. Do mesmo modo, foi atribuído um peso igual para as áreas correspondentes à água e às nuvens, por não terem nenhuma influência sobre processos estudados. O peso 2 , por sua vez, foi relacionado às zonas de vegetação secundária, tendo em vista que este tipo de cobertura corresponde à vegetação alterada, em diferentes níveis, formadas por campos, árvores espaçadas e demais indivíduos. O peso 3 foi atribuído às áreas urbanizadas, pois possuem influência determinante sobre os processos estudados.

No mapa de solos, os Argissolos e Neossolos receberam peso máximo, pelo fato de serem bastante suscetíveis à erosão. No caso dos Argissolos, a impermeabilidade do horizonte B textural permite que o material arenoso 
sobreposto seja facilmente removido. Na situação dos Neossolos, sua constituição predominantemente arenosa facilita a permeabilidade e, por conseguinte, à erosão. Os Espodossolos foram considerados como de nível intermediário, pois embora possuam certo nível de suscetibilidade à erosão, estão restritos aos topos dos tabuleiros costeiros, onde a infiltração predomina sobre o transporte e a erosão. Os Organossolos e a área de mineração receberam peso 1 devido ao fato de não terem participação considerável nos processos estudados.

Por fim, para o mapa de exposição de vertentes, foram atribuídos os pesos 3 às vertentes voltadas para sudeste, leste e nordeste, pelo fato de receberem maior influência dos ventos alísios. As vertentes opostas, por sua vez, receberam peso 1 , enquanto as vertentes norte e sul receberam peso intermediário.

Após a definição dos pesos, foi realizado o processo de álgebra a partir da seguinte equação:

\section{$([$ declividade $] \times 0,35)+([$ ocupação do solo $] \times 0,30)+([\operatorname{solos}] \times 0,20)+$ ([exposição de vertentes] $x 0,15$ )}

\section{Resultados}

No município de João Pessoa, os bairros mais importantes do ponto de vista econômico encontram-se localizados sobre o topo dos tabuleiros costeiros ou próximos às planícies costeiras. Por outro lado, os bairros menos favorecidos economicamente distribuem-se, principalmente, sobre as vertentes, planícies fluviais e depressões fechadas, onde os processos de riscos são mais atuantes.

O mapa de declividade revelou importantes informações acerca das áreas suscetíveis à erosão e movimentos de massa, pois possui grande influência sobre a ocorrência desses processos, devido a influência da gravidade (figura 3).

$\mathrm{Na}$ área de estudo, algumas regiões merecem destaque, pois a ocorrência de vertentes com elevado grau de declividade oferecem riscos às populações residentes nesses locais. A partir do mapa de declividade foi possível constatar a predominância das categorias: plano (0-3\%) e suave plano (3-8\%), perfazendo cerca de $181,45 \mathrm{~km}^{2}$, correspondendo a $91,1 \%$ da área total. Isto se deve ao fato de que o relevo predominante na área é constituído por tabuleiros litorâneos. 
Saulo Roberto de Oliveira Vital, Bruno Ferreira, Osvaldo Girão, Caio Lima dos Santos, Fábio Carvalho Nunes. Cartographic digital base as a tool for identifying areas prone to erosion and mass movement in João Pessoa (PB), Brazil

Figura 3. Mapa de declividade do município de João Pessoa (PB)

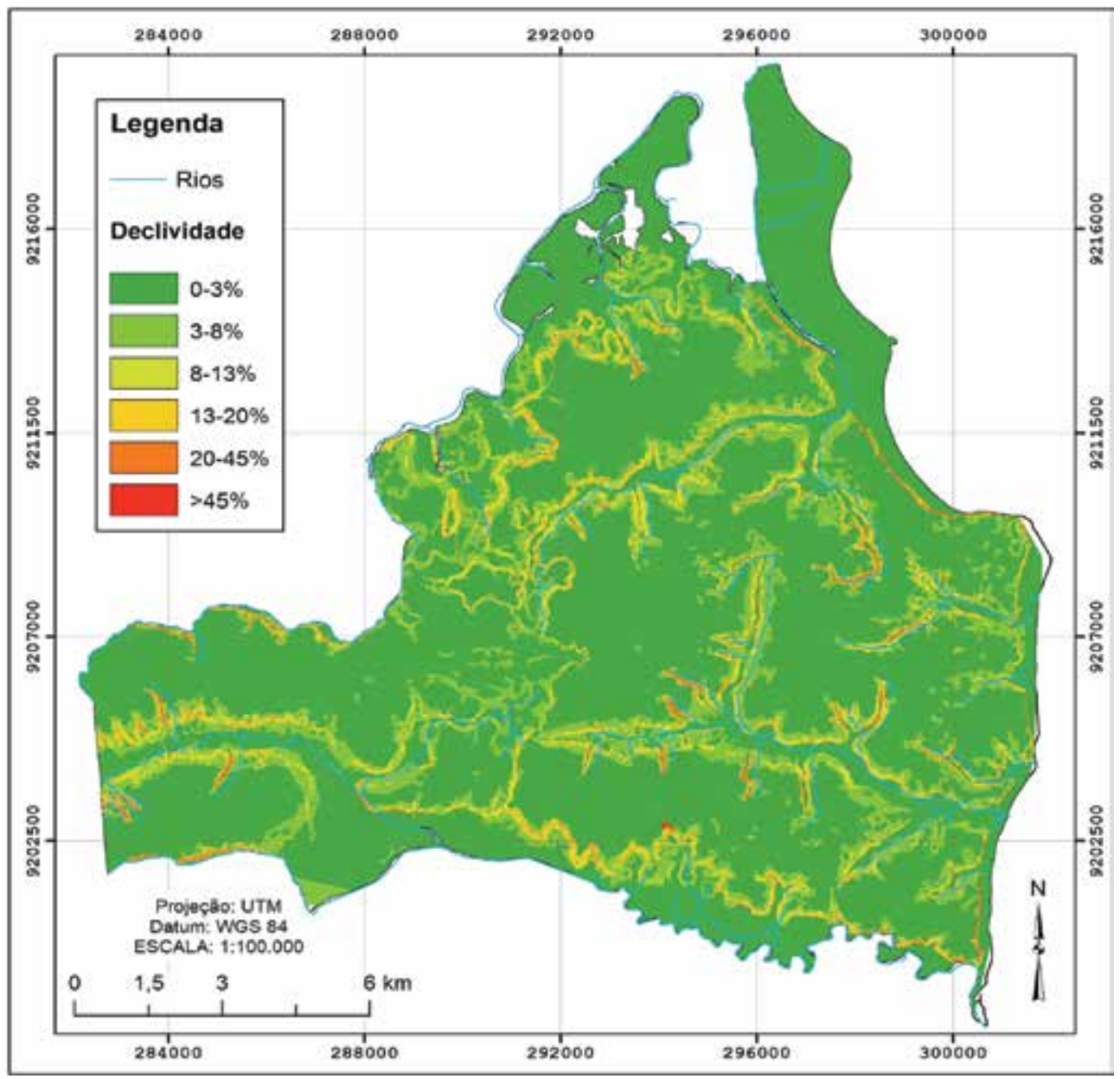

Fonte: elaborado pelos autores.

As zonas de maior inclinação coincidem com as vertentes que limitam os rios da região, tais como o Jaguaribe, Cuiá, Marés e Mumbaba, onde se verifica a ocorrência das classes: moderadamente ondulado (8$13 \%$ ), ondulado (13-20\%), forte ondulado (20-45\%) e escarpado $(>45 \%)$, perfazendo, juntas, $17,71 \mathrm{~km}^{2}$, totalizando $8,9 \%$ (tabela 3 ). 
Tabela 3. Percentual das áreas correspondentes às classes de declividade

\begin{tabular}{|l|c|c|c|}
\hline \multicolumn{1}{|c|}{ Classes } & Intervalos $\mathbf{( \% )}$ & Área $\left.\mathbf{( k m}^{\mathbf{2}}\right)$ & Percentual \\
\hline Plano & $0-3$ & 149,14 & $74,88 \%$ \\
\hline Suave ondulado & $3-8$ & 32,31 & $16,22 \%$ \\
\hline Moderadamente ondulado & $8-13$ & 9,67 & $4,86 \%$ \\
\hline Ondulado & $13-20$ & 5,06 & $2,54 \%$ \\
\hline Forte ondulado & $20-45$ & 2,83 & $1,42 \%$ \\
\hline Escarpado & $>45$ & 0,15 & $0,08 \%$ \\
\hline
\end{tabular}

Fonte: elaborado pelos autores.

O mapa de exposição de vertentes revelou importantes informações acerca da orientação das encostas na área de estudo e como este quadro pode influenciar nos processos de erosão e movimentos de massa. Certamente, aquelas encostas que se encontram voltadas para sudeste, leste e até mesmo nordeste terão maior suscetibilidade à ocorrência desses processos, devido à ação dos ventos litorâneos, em períodos de maior intensidade pluviométrica (figura 4).

Foi detectado que $6,9 \%$ das encostas estão voltadas para sudeste, que consiste na porção mais suscetível à ocorrência de eventos chuvosos extremos. As vertentes leste e nordeste, que possuem um grau semelhante de risco, abrangem $14,3 \%$ da área estudada. O restante das classes, por sua vez, abrangem $28,7 \%$, enquanto as áreas planas abrangem metade da área do município de João Pessoa, com exatos 50\% (tabela 4).

Isto demonstra que, $22 \%$ da área total apresenta alta vulnerabilidade à ação dos ventos úmidos litorâneos, o que eleva os riscos de erosão e movimentos de massa, principalmente em regiões urbanizadas.

A exposição de vertentes constitui uma variável importante na análise do risco, embora ainda seja pouco incluída em estudos voltados à este tipo de análise. 
Saulo Roberto de Oliveira Vital, Bruno Ferreira, Osvaldo Girão, Caio Lima dos Santos, Fábio Carvalho Nunes. Cartographic digital base as a tool for identifying areas prone to erosion and mass movement in João Pessoa (PB), Brazil

Figura 4. Mapa de exposição de vertentes do município de João Pessoa (PB)

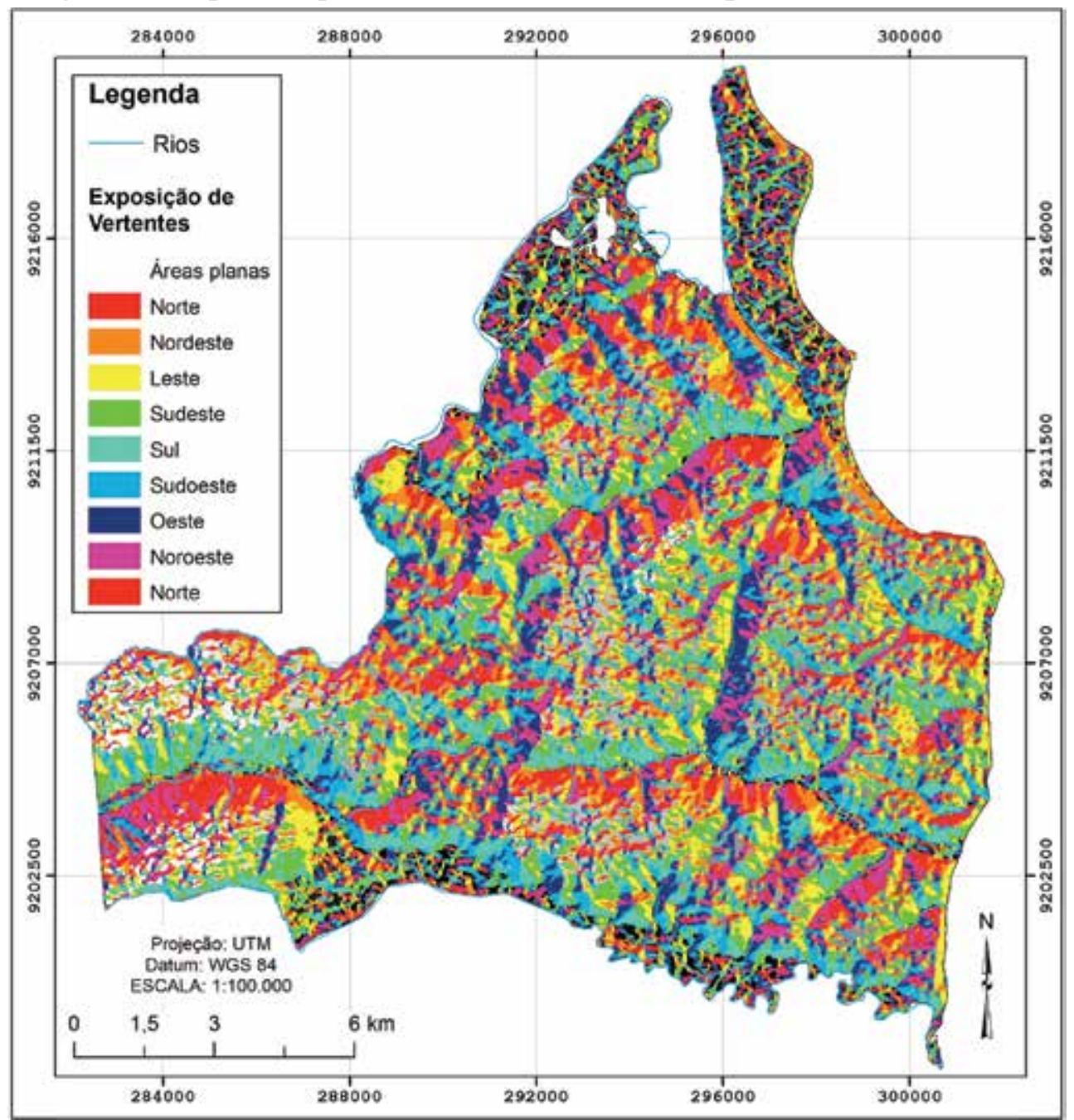

Fonte: elaborado pelos autores. 

cartográfica digital como instrumento para a identificação de áreas suscetíveis à erosão e movimentos de massa em João Pessoa (pb), Brasil

Tabela 4. Percentual das áreas correspondentes às classes de exposição de vertentes

\begin{tabular}{|l|c|c|}
\hline \multicolumn{1}{|c|}{ Classes } & Área $\left.\mathbf{( k m}^{\mathbf{2}}\right)$ & Percentual \\
\hline Norte & 13,46 & $7,1 \%$ \\
\hline Nordeste & 12,02 & $6,3 \%$ \\
\hline Leste & 15,21 & $8 \%$ \\
\hline Sudeste & 13,22 & $6,9 \%$ \\
\hline Sul & 13,29 & $7 \%$ \\
\hline Sudoeste & 9,08 & $4,7 \%$ \\
\hline Oeste & 8,75 & $4,6 \%$ \\
\hline Noroeste & 10,13 & $5,3 \%$ \\
\hline Áreas planas & 94,10 & 50,01 \\
\hline
\end{tabular}

Fonte: elaborado pelos autores.

A partir da base fornecida pela EMBRAPA, Solos UEP Recife (2006), na escala de 1:400.000, com auxílio das curvas de nível e da imagem OLI/Landsat, tornou-se possível obter informações acerca da distribuição dos solos na área de estudo, onde foram detectados os seguintes tipos: Argissolos, Espodossolos, Organossolos e Neossolos (figura 5). 
Saulo Roberto de Oliveira Vital, Bruno Ferreira, Osvaldo Girão, Caio Lima dos Santos, Fábio Carvalho Nunes. Cartographic digital base as a tool for identifying areas prone to erosion and mass movement in João Pessoa (PB), Brazil

Figura 5. Mapa de solos do município de João Pessoa

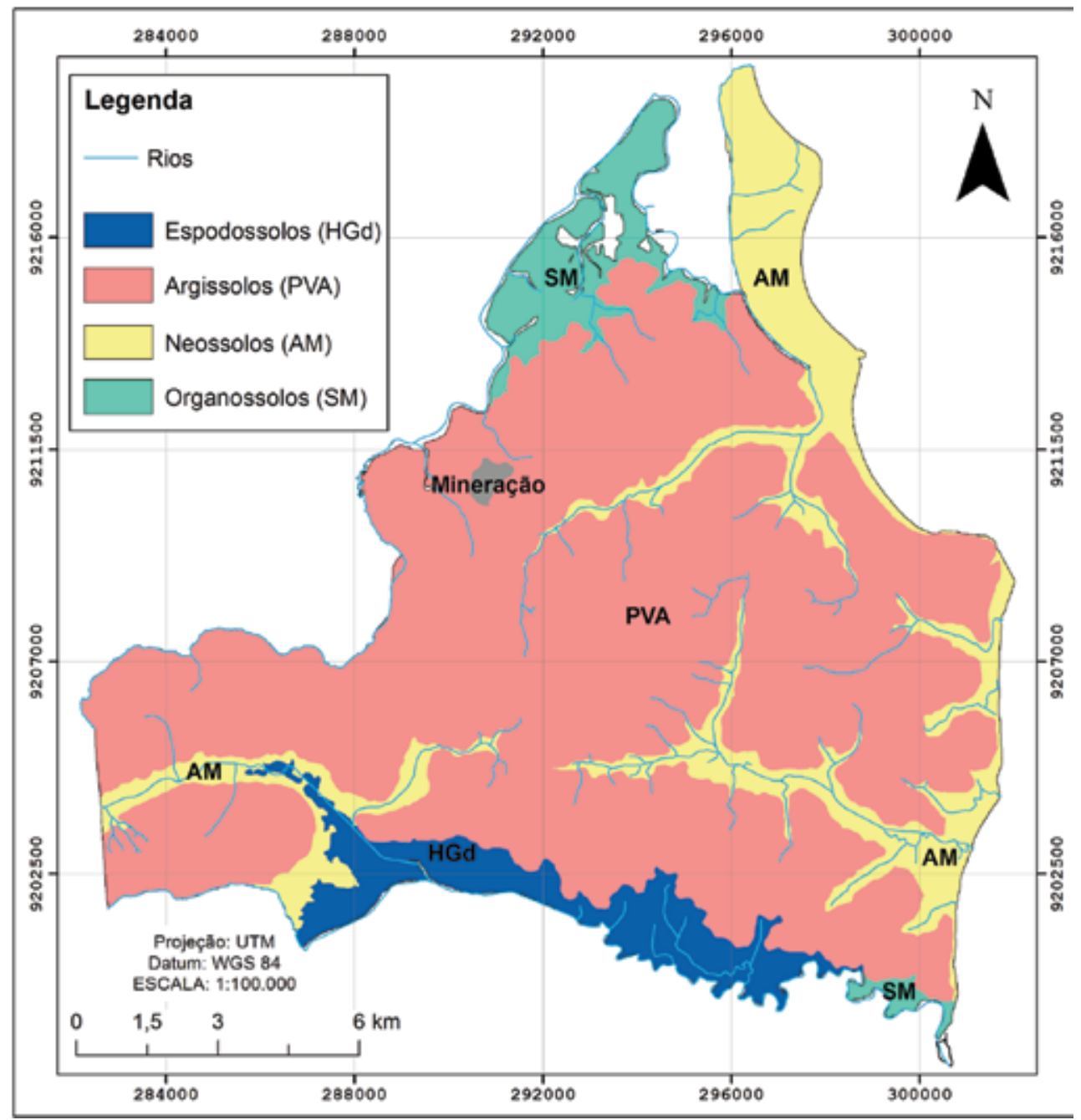

Fonte: elaborado pelos autores.

O Argissolo Amarelo corresponde ao tipo de solo predominante na área estudada, tendo a ocorrência de concreções ferruginosas como uma de suas principais características. Neste solo, o horizonte B se apresenta bastante endurecido quando seco, mas torna-se friável ao entrar em contato com a água, tornando-se mais suscetível à ocorrência de movimentos de massa. De fato, este é um fator importante na compreensão dos riscos 
que se desenvolvem no município de João Pessoa. A existência de níveis endurecidos em um ambiente predominantemente plano e suave ondulado permite uma maior estabilidade, porém, nas zonas de maior declividade, o nível de risco aumentará em virtude da ação da gravidade, onde deve-se ter maiores cuidados em relação à ocupação. Outrossim, a presença de lençóis suspensos favorecidos pela ocorrência ne níveis endurecidos subsuperficiais pode conferir maior instabilidade a estas coberturas.

A utilização das curvas de nível do terreno tornou possível a delimitação das áreas com ocorrência de Neossolos, proporcionando uma definição mais precisa dos limites entre as classes de solos, gerando informações numa escala de maior detalhe (1:100.000). Contudo, o referido mapa não passou por um processo de refinamento com base em trabalhos de campo, mas unicamente a partir das informações altimétricas, no intuito de compatibilizar sua escala a dos demais mapas.

Os Espodossolos também ocorrem na área de estudo, numa estreita faixa a sul, correspondendo à uma zona próxima ao leito do rio Gramame, conforme pode ser observado no mapa. Entretanto, também ocorrem em forma de manchas no topo dos Tabuleiros Costeiros, atravancando a predominância dos Argissolos. Essas coberturas pedológicas têm a sua origem por força do predomínio da infiltração numa região úmida e plana, onde a água é capaz de transportar constituintes de alumínio e ferro por eluviação, deixando o quartzo na superfície, o que resulta em paisagens dominadas por areias brancas.

Os Organossolos estão restritos às zonas de manguezais, apresentando pouca evolução, presença de muita matéria orgânica, além de cores escuras ou cinza escura. São solos que oferecem riscos frente à ocupação, mas em relação à ocorrência de erosão e movimentos de massa, são irrelevantes.

Os Neossolos, por fim, distribuem-se nas áreas costeiras, na região que compreende a planície fluviomarinha de Cabedelo, e nas várzeas fluviais dos rios Jaguaribe, Marés e Cuiá.

O mapa de cobertura do solo revelou uma extensa área urbanizada, com $98,7 \mathrm{~km}^{2}$, correspondendo a 48,3\% da área total. As áreas florestais abrangem $35,1 \mathrm{~km}^{2}$, perfazendo cerca de $17 \%$ do total de cobertura do solo. Essas áreas compreendem as unidades de conservação, a exemplo da Mata do buraquinho, localizada na porção central do município. O restante do percentual, 34,3\%, corresponde às áreas de vegetação secundária, 
Saulo Roberto de Oliveira Vital, Bruno Ferreira, Osvaldo Girão, Caio Lima dos Santos, Fábio Carvalho Nunes. Cartographic digital base as a tool for identifying areas prone to erosion and mass movement in João Pessoa (PB), Brazil

corpos d'água e nuvens, que também inclui áreas não classificadas devido às sombras (tabela 5).

O mapa demonstra o claro avanço da urbanização no município de João Pessoa, com destaque para a região centro-norte. Além disso, percebe-se a pressão da zona urbana sobre as áreas vegetadas (figura 6).

Figura 6. Mapa de cobertura do solo no município de João Pessoa (PB)

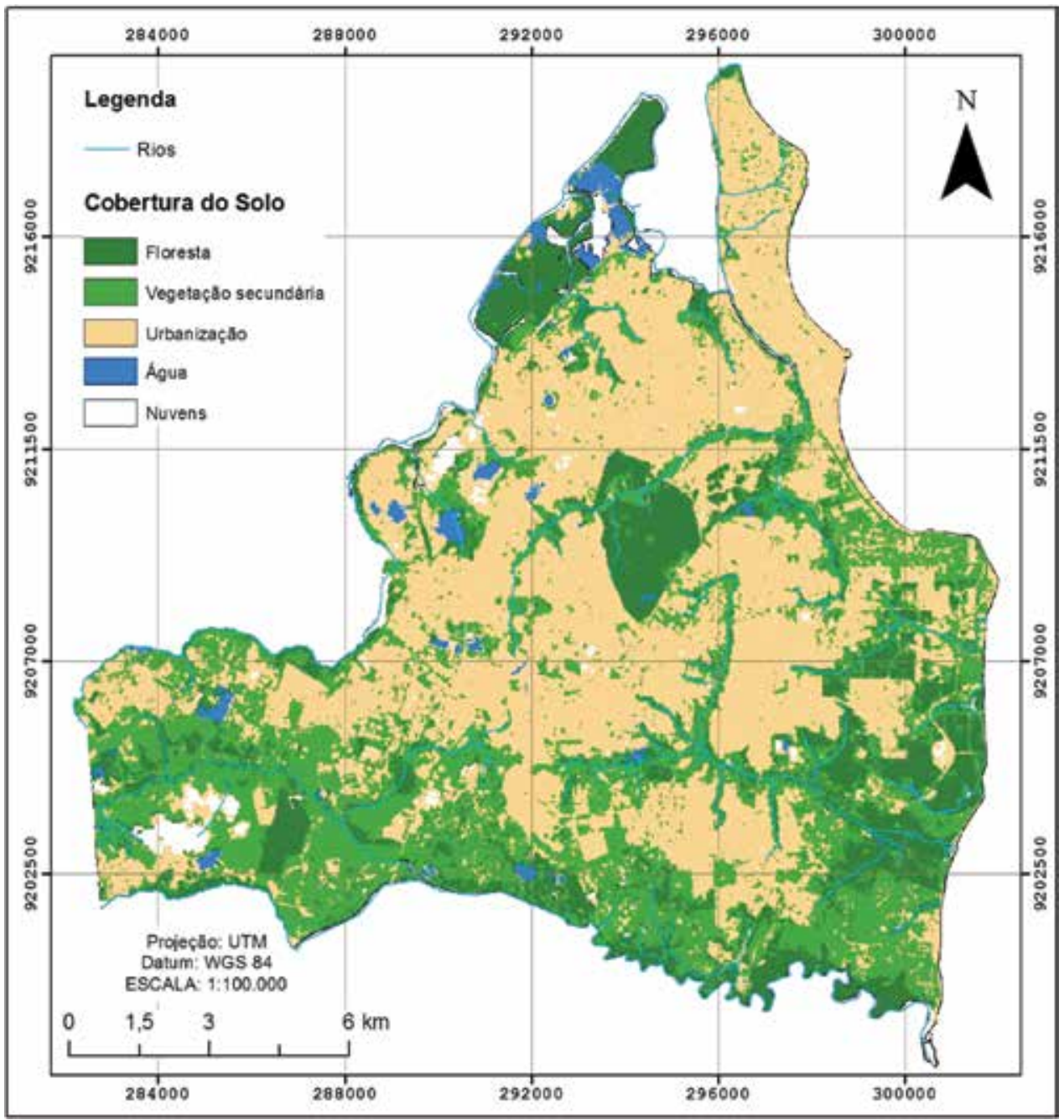

Fonte: elaborado pelos autores. 

cartográfica digital como instrumento para a identificação de áreas suscetíveis à erosão e movimentos de massa em João Pessoa (pb), Brasil

Tabela 5. Percentual das áreas correspondentes às classes de cobertura de solo

\begin{tabular}{|l|c|c|}
\hline \multicolumn{1}{|c|}{ Classes } & Área $\mathbf{( k m}^{\mathbf{2}} \mathbf{)}$ & Percentual (\%) \\
\hline Florestas & 35.156 & 17,229 \\
\hline Vegetação secundária & 63.924 & 31,327 \\
\hline Urbanização & 98.728 & 48,384 \\
\hline Água & 5.262 & 2,578 \\
\hline Nuvens & 0.989 & 0,484 \\
\hline Área total & 204.05 & 100 \\
\hline
\end{tabular}

Fonte: elaborado pelos autores.

O mapa das zonas suscetíveis à ocorrência de erosão e movimentos de massa revelou que $65,72 \%$ da área do município pode ser classificada como detentora de risco médio, enquanto $30,53 \%$ corresponde ao risco baixo e apenas $3,75 \%$ correspondem às zonas de risco alto (tabela 6 ).

Tabela 6. Percentual das áreas suscetíveis à erosão e movimentos de massa

\begin{tabular}{|l|c|c|}
\hline \multicolumn{1}{|c|}{ Classes } & Área $\mathbf{( k m}^{\mathbf{2}}$ ) & Percentual \\
\hline Baixo & 61,67 & 30,53 \\
\hline Médio & 132,77 & 65,72 \\
\hline Alto & 7,58 & 3,75 \\
\hline
\end{tabular}

Fonte: elaborado pelos autores.

O mapa demonstrou que as zonas mais propensas aos processos de erosão e movimentos de massa são justamente aquelas que se encontram localizadas nas vertentes íngremes que limitam os vales dos principais rios da cidade.

Foram selecionadas algumas áreas consideradas representativas do ponto de vista da ocorrência de erosão e movimentos de massa no município de João Pessoa, são elas: bairro São José (1), comunidade Saturnino de Brito no bairro Trincheiras (2), comunidade Santa Clara no bairro Castelo Branco (3), comunidade Timbó no bairro Bancários (4) e Av. Coronel Estevão D’ávila no vale do rio Jaguaribe, bairro Cruz das Armas (5). Todas essas áreas, dentre outras, foram classificadas no mapa como detentoras de risco máximo (alto) para a ocorrência de erosão e movimentos de massa (figura 7). 
Saulo Roberto de Oliveira Vital, Bruno Ferreira, Osvaldo Girão, Caio Lima dos Santos, Fábio Carvalho Nunes. Cartographic digital base as a tool for identifying areas prone to erosion and mass movement in João Pessoa (PB), Brazil

As zonas de risco médio correspondem aos pontos densamente urbanizados. Certamente, no processo de álgebra de mapas, o peso atribuído à cobertura do solo foi decisivo na delimitação dessas áreas.

Do mesmo modo, as zonas de baixo risco obedecem sistematicamente às zonas florestais, tais como a Mata do Buraquinho, localizada na porção central do município e demais áreas de preservação que ocupam determinados pontos do município, assim como a zona de manguezais.

Figura 7. Mapa das áreas suscetíveis à ocorrência de erosão e movimentos de massa no município de João Pessoa (PB)

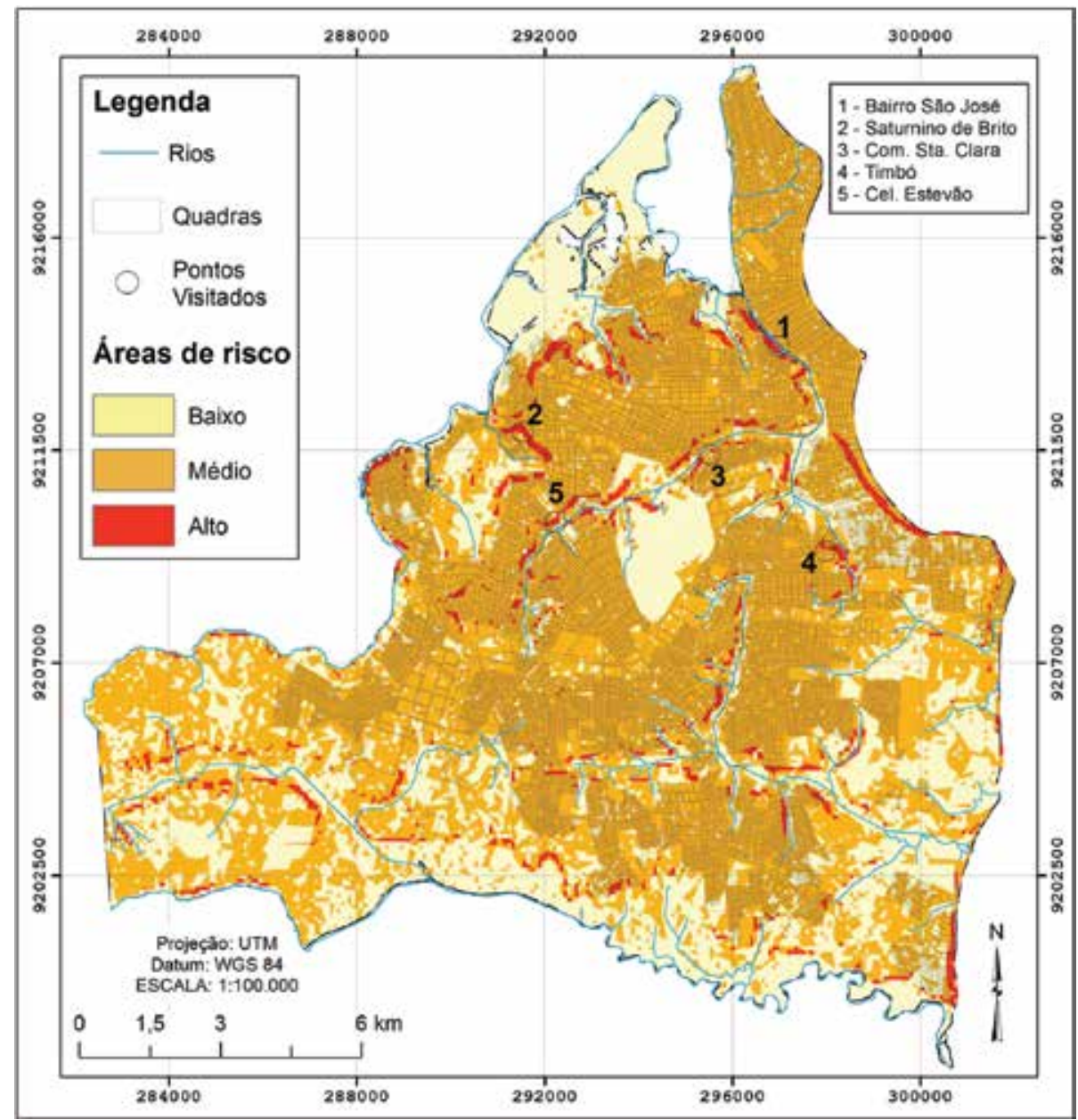

Fonte: elaborado pelos autores. 
Os lotes urbanos foram inseridos no mapa para proporcionar a visualização da zona urbana sobre as áreas de risco.

\section{Discussão}

De maneira geral, os processos geradores de riscos observados no município de João Pessoa são basicamente representados por erosões lineares e por movimentos de massa causados por desmonte nas encostas e terraços fluviais. Além dos riscos de natureza hidrológica, tais como: alagamentos, enchentes e inundações.

As feições erosivas ocorrem como consequência de um sistema inadequado de drenagem e pela falta de pavimentação. A impermeabilização do solo no topo dos tabuleiros costeiros contribui com o aumento da energia do escoamento superficial devido à drástica redução da infiltração, culminando na formação de ravinas e voçorocas, na porção da inflexão topo/encosta.

Os pontos com ocorrência de movimentos de massa, por sua vez, devem-se à existência de cortes e aterros indevidos, sem a realização de obras de contenção.

No bairro São José, por exemplo, muitas residências encontram-se localizadas junto ao sopé das encostas, onde também se verifica a supressão da vegetação nativa. Em outros pontos, a ocorrência de árvores de grande porte atua como um fator de intensificação dos riscos, devido ao sobrepeso, principalmente em períodos de maior intensidade pluviométrica. Os riscos de inundações também constitui um fenômeno marcante na área em estudo, demonstrado na figura 8.

Neste bairro, existem famílias que residem em moradias precárias, onde existem árvores na eminência de tombamentos, pontes de madeira que ameaçam desabar, além de riscos de proliferação de doenças causadas pelo acúmulo de lixo no local.

Na Comunidade Saturnino de Brito, localizada no bairro Trincheiras, as moradias se distribuem ao longo de bordas íngremes de um extenso anfiteatro, onde são observadas escavações do topo e sopé das encostas, lançamento de dejetos e águas servidas na barreira, moradias precárias localizadas juntas ao muro de arrimo, árvores na eminência de tombamento e galerias obstruídas desaguando sobre a encosta. 
Saulo Roberto de Oliveira Vital, Bruno Ferreira, Osvaldo Girão, Caio Lima dos Santos, Fábio Carvalho Nunes. Cartographic digital base as a tool for identifying areas prone to erosion and mass movement in João Pessoa (PB), Brazil

A comunidade Santa Clara, localizada às margens da BR-230, no bairro Castelo Branco, também constitui outra área de risco bastante representativa no município de João Pessoa.

Figura 8. Moradias em situação de risco no bairro São José, João Pessoa (PB)

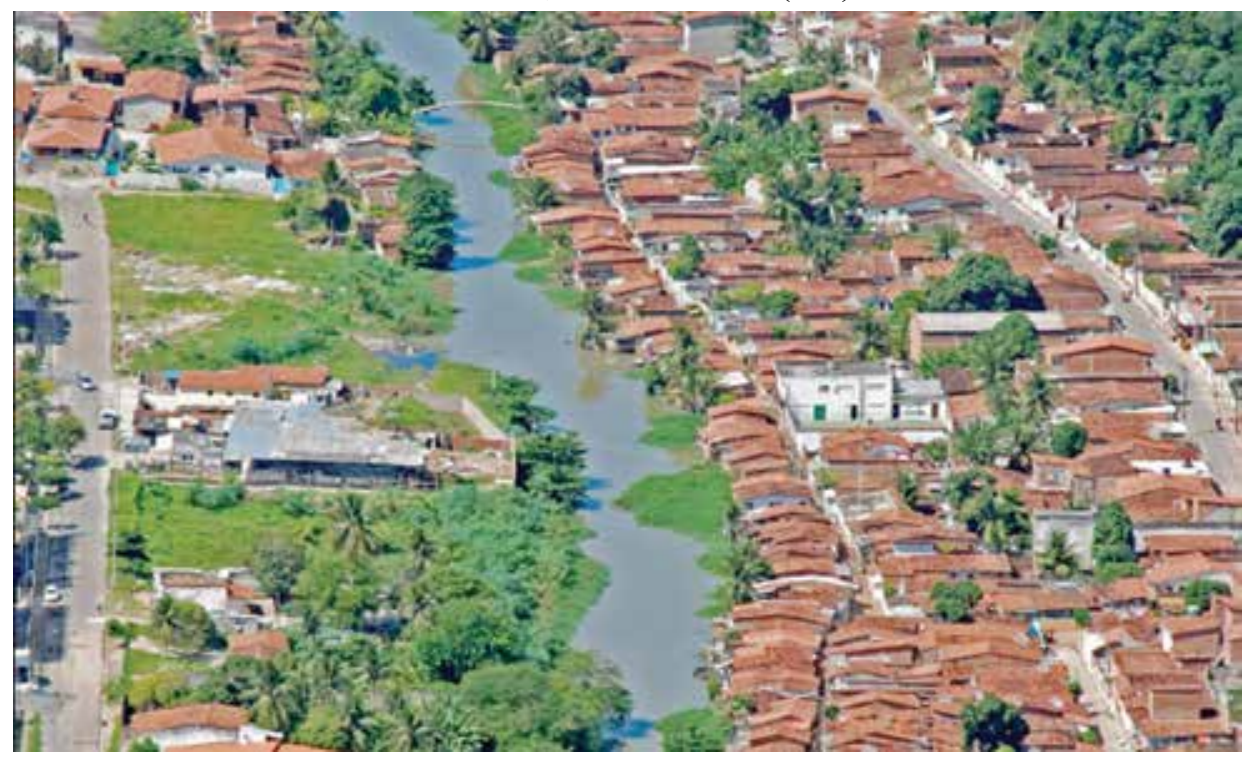

Fonte: Prefeitura Municipal de João Pessoa, 2011.

Neste local, foram observados fortes declives em função de um corte realizado nos terraços do rio Jaguaribe para a locação da rodovia BR-230. Isto contribuiu para a ocorrência de escorregamentos, pondo em risco os veículos que aí trafegam e aos moradores que residem no topo da encosta.

Nesta localidade, foram observados processos de escorregamentos do talude em virtude da forte inclinação do terreno que excede o limite de resistência ao cisalhamento nas condições de presença de água, dando origem a cicatrizes de rupturas circulares (figura 8).

A inserção de lonas para evitar o escoamento superficial diretamente sobre os sedimentos da encosta constitui uma solução paliativa, sendo necessária a realização de obras de retaludamento e a retirada imediata da população que reside próximo à inflexão topo/encosta, visando evitar novas perdas e danos materiais. 
Figura 9. Cicatriz de ruptura circular em corte realizado em encostas da Com. Santa Clara

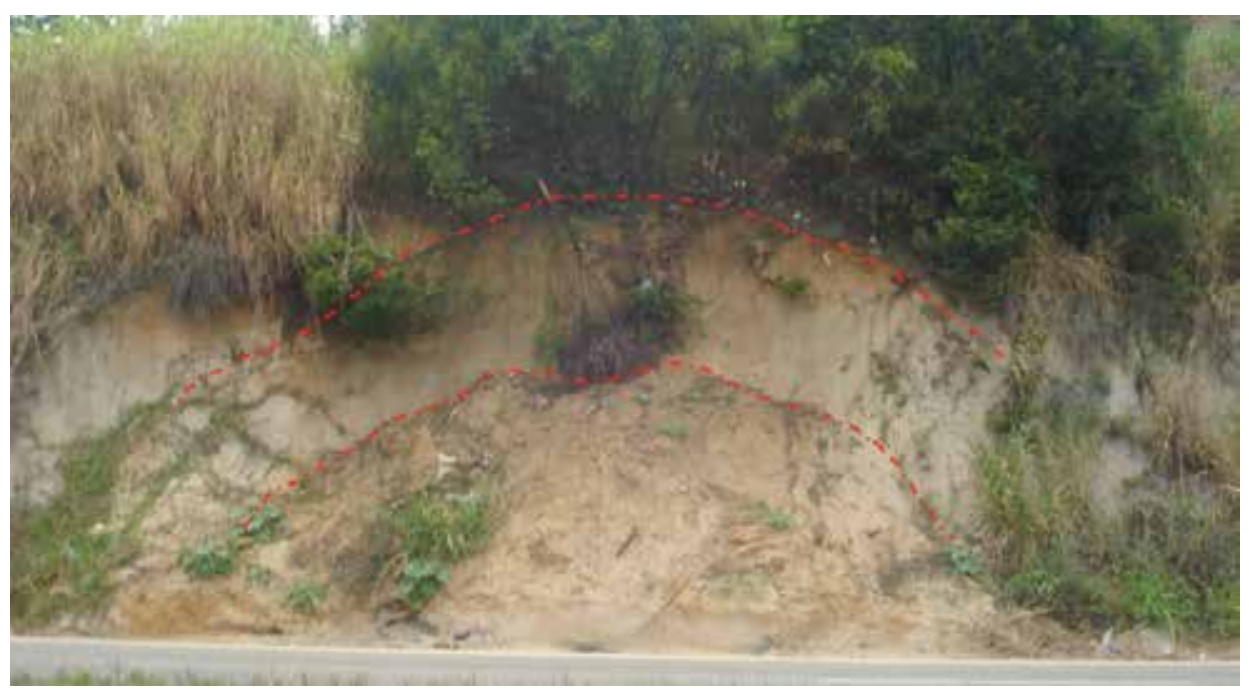

Foto: Vital, 2015.

Na comunidade do Timbó, também foram encontrados os mesmos processos que ocorrem na comunidade Saturnino de Brito, porém foi observada a execução de obras de retaludamento para a contenção dos movimentos de massa.

Em relação aos casos de erosão, destaca-se a ocorrência de grandes ravinamentos nas vertentes do rio Jaguaribe, a exemplo do processo que tem se desenvolvido na Av. Coronel Estevão D'ávila, no bairro Cruz das Armas.

A ocorrência de feições desta natureza, deve-se ao constante lançamento de efluentes domésticos sobre a encosta, causando erosão hídrica acelerada e a formação grandes ravinas, causando, dentre outras consequências, o assoreamento do rio (Figura 10).

De forma geral, pode-se afirmar que, ao contrário das cidades localizadas nas regiões sul e sudeste do Brasil, onde um manto de intemperismo repousa diretamente sobre a rocha cristalina, criando um cenário favorável a movimentos de massa, em João Pessoa, a planura do terreno atrelada ao baixo índice de dissecação do relevo no contexto de uma bacia sedimentar, inibe a ação de tais processos. Além disso, a presença marcante de níveis ferruginosos no solo confere certa estabilidade ao ambiente, que é rompida 
Saulo Roberto de Oliveira Vital, Bruno Ferreira, Osvaldo Girão, Caio Lima dos Santos, Fábio Carvalho Nunes. Cartographic digital base as a tool for identifying areas prone to erosion and mass movement in João Pessoa (PB), Brazil

pela ação dos efluentes domésticos lançados initerruptamente sobre as vertentes e por cortes e aterros indevidos.

Figura 10. Ocorrência de processo erosivo em encosta do rio Jaguaribe, na rua Coronel Estevão D’ávila

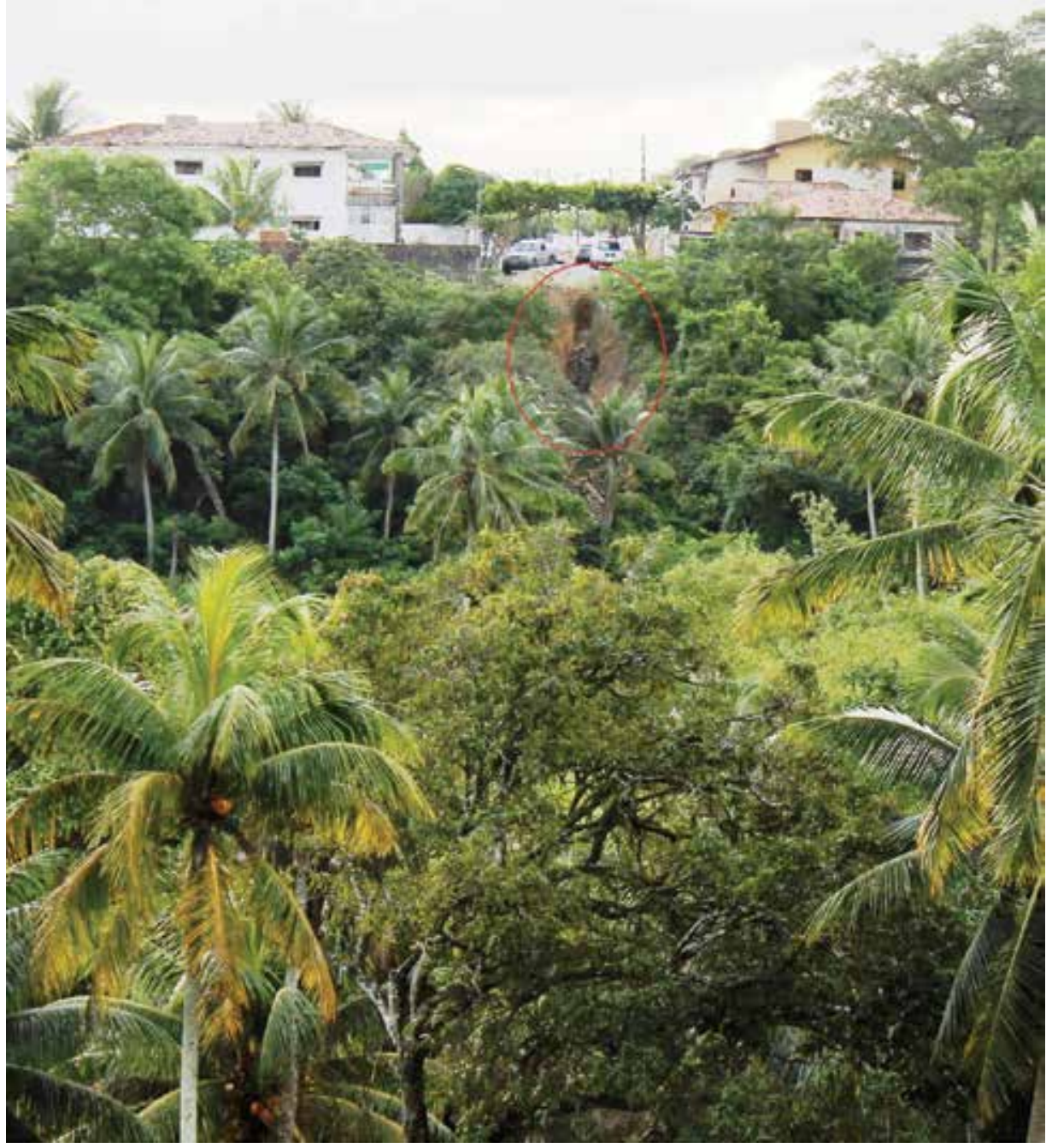

Foto: Vital, 2013. 


\section{Conclusões}

A utilização de diferentes bases cartográficas para o mapeamento dos riscos de erosão e movimentos de massa no município de João Pessoa, a partir de técnicas de geoprocessamento, demonstrou-se bastante eficaz, uma vez que apresentou ótima resposta frente aos fenômenos observados nos trabalhos de campo.

Foi possível constatar que os processos analisados encontram-se fortemente influenciados pela urbanização, uma vez que tanto as feições erosivas quanto os movimentos de massa ocorrem em função do uso inapropriado do relevo. Neste caso, pode-se citar o caso das feições erosivas elaboradas a partir da erosão hídrica acelerada, devido a destinação incorreta de efluentes domésticos, que são lançados diretamente sobre as encostas, e a ocorrência de movimentos de massa em função de cortes e aterros elaborados de maneira incorreta.

Por esse motivo, este trabalho visa contribuir com a gestão ambiental e territorial do município de João Pessoa, sugerindo um controle maior sob a expansão urbana, através de iniciativas que visem conter o avanço de tais processos.

Desse modo, o mapa de riscos apresentado neste trabalho pretende fornecer subsídios para o planejamento do meio físico, visando contribuir com futuras reestruturações do plano Diretor Municipal do município de João Pessoa, no que se refere ao parcelamento do solo urbano, servindo como base para projetos de loteamentos em áreas de alto risco.

\section{Referências}

Araújo Filho, J. (2003). Horizontes cimentados em Argissolos e Espodossolos dos tabuleiros costeiros e em Neossolos Regolíticos e Planossolos da depressão sertaneja do Nordeste do Brasil. Tese (doutorado em Geoquímica e Geotectônica) - Instituto de Geociências da Universidade de São Paulo. São Paulo. 223p.

Barbosa, J. (2003). A deposição carbonática na faixa costeira Recife-Natal: aspectos estratigráficos, geoquímicos e paleontológicos. Tese (doutorado em Geociências) - Centro de Tecnologia e Geociências da Universidade Federal de Pernambuco. Recife. 264p.

Campos, M. \& Queiroz, S. (2006). Reclassificação dos perfis descritos no Levantamento Exploratório-Reconhecimento de Solos do Estado da 
Paraíba. São Cristóvão. Revista de Biologia e Ciências da Terra, 6(1), 45-50.

Carvalho, M. (1982). Estado da Paraíba: classificação geomorfológica. João Pessoa: UFPB.

Cipriano-Silva, R., Valladares, G., Pereira, M. \& Anjos, L. (2014). Caracterização de Organossolos em ambientes de várzea do Nordeste do Brasil. Revista Brasileira de Ciência do Solo, 38, 26-38.

Empresa Brasileira de Pesquisa Agropecuária/Unidade de Execução e Pesquisa em Recife, (EMBRAPA/UEP Recife). (2006). Solos do Nordeste. Recuperado de www.uep.cnps.embrapa.br/solos/index.html.

Garcia, R., Zêzere, J., Oliveira, S. \& Reis, E. (2007). A importância do processo de classificação de dados na cartografia: um exemplo na cartografia de susceptibilidade a movimentos de vertente. Publicações da Associação Portuguesa de Geomorfólogos, 5, 265-279.

Girão, O., Corrêa, A., Nóbrega, R. \& Duarte, C. (2013). O Papel do Clima nos Estudos de Prevenção e Diagnóstico de Riscos Geomorfológicos em Bacias Hidrográficas na Zona da Mata Sul de Pernambuco. In: Guerra, A. \& Oliveira- Jorge, M. (Eds.). Erosão e Movimentos de Massa: Recuperação de Áreas Degradadas e Prevenção de Acidentes. São Paulo: Oficina de Textos.

Guerra, A. (2011). Geomorfologia Urbana. Rio de Janeiro: Bertrand Brasil. Guerra, A. \& Marçal, M. (2006). Geomorfologia Ambiental. Rio de Janeiro: Bertrand Brasil.

Instituto Brasileiro de Geografia e Estatística. (IBGE). (2010). Censo. Recuperado de http://cidades.ibge.gov.br/painel/painel. php?codmun $=250750$.

Mabesoone, J. \& Rolim, J. (1982). Problemas estratigráficos e sedimentológicos do Cenozóico nordestino. Estudos Pesquisas, 5, 7-18.

Macedo, E. (2001). Elaboração de cadastro de risco eminente relacionado a escorregamentos: avaliação considerando a experiência profissional. Tese (doutorado em Geociências e Meio Ambiente) - Instituto de Geociências e Ciências Exatas da Universidade Estadual Paulista. Rio Claro, SP.

Melo, A., Heckendorff, W., Alves, E. \& Guimarães, M. (2001). O meio ambiente natural: componentes abióticos e bióticos. In: Melo, A. (Eds.). Projeto de Pesquisa: Vale do Jaguaribe. João Pessoa: UNIPÊ. 
Mendonça, I., Lombardi-Neto, F. \& Viégas, R. (2006). Classificação da capacidade de uso das terras da Microbacia do Riacho Una, Sapé, PB. Revista Brasileira de Engenharia Agrícola e Ambiental, 10(4), 888-895.

Oliveira, F. (2001) Degradação do meio físico e implicações ambientais na bacia do rio Jaguaribe - João Pessoa - PB. Dissertação (mestrado em Geociências) - Centro de Tecnologia e Geociências da Universidade Federal de Pernambuco. Recife. 95p.

Pereira, L. \& Lombardi-Neto, F. (2004). Avaliação da Aptidão Agrícola das Terras: proposta metodológica. Jaguariúna, SP: EMBRAPA.

Pereira, M., Monteiro, D., Silva, N. \& Moura, M. (2012). Avaliação quantitativa das precipitações diárias intensas na cidade de João Pessoa, Paraíba. Revista Geonorte, 1(5), 921-929.

Pereira, M. \& Alves, R. (2007). Composição florística de um remanescente de Mata Atlântica na Área de Proteção Ambiental Barra do Rio Mamanguape, Paraíba, Brasil. Revista de Biologia e Ciências da Terra, 7(1), 1-10.

Prefeitura Municipal de João Pessoa (PMJP). (2015). Jampa em Mapas. Recuperado: http://geo.joaopessoa.pb.gov.br/digeoc/htmls/.

Rosa, P. Perfil socioeconômico da população dos aglomerados de quatro compartimentos topográficos de João Pessoa (PB): diagnóstico elementar. 2003. Recuperado:http://www.geociencias.ufpb. br/ paulorosa/Documentos/Projetos_e_diagnosticos/Diag_Socio_ EconAglomSub-NormaisJPA.pdf.

Santos, C., Wanderley, L., Vital, S. \& Girão, O. (2015). Análise da suscetibilidade à ocorrência de enchentes e alagamento na bacia do alto/ médio curso do rio Jaguaribe, João Pessoa/PB, a partir de características morfométricas extraídas de dados SRTM. Revista de Geociências do Nordeste, 1(1), 37-49.

Spera, S., Reatto, A., Martins, E., Correia, J. \& Cunha, T. (1999). Solos areno-quartzosos do Cerrado: características, problemas e limitações ao uso. Planaltina: Embrapa-CPAC. 